\title{
History of Media Studies, in the Plural
}

\author{
David W. Park (iD \\ Lake Forest College, park@lfc.edu \\ Jefferson Pooley
}

Muhlenberg College, pooley@muhlenberg.edu

\section{Peter Simonson (iD}

University of Colorado Boulder, peter.simonson@colorado.edu

WE LAUNCH History of Media Studies with a concession that is also a confession: The journal's object, the history of media studies, is porous and tensile, verging on shapeless. The main reason is that "media studies" itself has no agreed-upon referent. The phrase only gained traction — as a singular, field-designating noun—in the late 1960s and 1970s, long after the study of media and communication had taken variable root in the university. There were "media studies" in the plural, but no such thing as a field by that name. Even today, many academics who work on topics related to media and communication would, if asked to name their field, give some other answer. Self-described "media studies" scholars, meanwhile, might squint quizzically at the field-definitions of their putative peers.

We take the term's slippages to be an editorial advantage. The journal's premise is that what counts as the history of media studies is itself up for grabs. The task of our authors, put another way, is to define the field's scope, through the accretion of their articles' arguments-by-example. There are disciplinary labels with more stable referents- "communication research" and "cinema studies" are two-but they are each partial enclosures. So one virtue of "media studies" is that it is porous and tensile.

Another virtue comes by way of the media concept itself. With roots dating back to at least the Enlightenment, medium and mediation
David W. Park, Jefferson Pooley, and Peter Simonson, "History of Media Studies, in the Plural," History of Media Studies 1 (2021), https://doi.org/ 10.32376/d895aoea.a2cf5b66.

History of Media Studies, vol. 1, 2021 
have become increasingly fundamental to understanding the social textures of the modern world. ${ }^{1}$ They are capacious concepts, at the center of all communicative processes-tied in one way to their materiality, in another to processes of representation, articulation, translation, and standing-between. The dominant, plural form of "media" - as commercial organs of mass communication-only took hold in the 1950s, at the height of the broadcast era. ${ }^{2}$ We invoke "media" in its rich, catholic sense, as an invitation to ventilate what the history of its study might be.

As a baseline, we expect to publish work that spans the history of the humanities and the social sciences. Scholarship on the history of communication research, cultural studies, film studies, information science, journalism studies, speech, and rhetoric will, we anticipate, feature in the editorial mix. Many of the subjects, discourses, and institutions that our authors investigate won't slot so easily. Scholars of media have identified with dozens of other disciplines, across local and national contexts barely represented in the published literature. Many students of media, moreover, were never affiliated with universities-working instead for commercial firms, government agencies, or nonprofit groups, or embedded within social movements. Our aim is to publish their stories too.

\section{Exclusions in the Historiography of Media Studies}

The mission of the journal is shaped by the historical moment. Our fields are belatedly reckoning with the legacies and ongoing consequences of an intersecting array of structural inequities: their whiteness and patriarchy; the hegemonies of the English language and of US forms of thinking and research; the longstanding effects of colonialism and anti-Blackness; the many forms of hierarchy and exclusion emanating from cores and peripheries around the globe; and the neoliberal colonization of universities and academic publishing, to name some of the most prominent. To this point, the bulk of critical writing on these subjects has rightly focused on their contemporary manifestations. History of Media Studies aims to provide a forum, too, for investigating the historical dynamics through which the media studies fields have reached this point-both in terms of dominant social patterns that have defined them and the mix of critical consciousness and alternative practices that might yield other ways of advancing our intellectual work. Beyond publishing such genealogies of the present, the journal is also committed to its own alternative practices and to supporting collective efforts that have energized the present moment.
${ }^{1}$ John Guillory, "Enlightening Mediation," in This is Enlightenment, ed. Clifford Siskin and William Warner (Chicago: University of Chicago Press, 2010).

\footnotetext{
${ }^{2}$ Anna Shechtman, "Command of Media's Metaphors," Critical Inquiry 47, no. 4 (2021).
} 
History of Media Studies aims to contribute to what might be called the de-centering of the centers within these interrelated patterns of marginalization. This will not be easy or straightforward work. The inherited habits of the field are lodged deep in its practices-and in the bodies and minds of those of us who work in it. Those habits cut across geopolitics, language, ideology, political economy, and the intersectionalities of social identity. All of these continue to unfold at a particularly perilous time in history, when deep inequalities, political crises, and climate change threaten the possibility of a shared, livable future on the planet. We have few illusions about the significance of a new scholarly journal in these contexts, and we do not want to overstate the importance of efforts it makes. That said, we believe that journals refract the wider practices and distortions of academic fields in microcosm, and they should do their parts in addressing broader calls of the present. A new journal can open at least modest space for thinking and doing things differently, serving as a small laboratory that might inform efforts elsewhere.

One might wonder how a journal whose founding editors are three white cis-men from the United States can in good faith hope to contribute to those efforts. We take those doubts seriously and in fact share them. The short response is that we could not hope to do much on our own. We resonate with Mohan Dutta's argument that we must design and enact different kinds of communication if we are to transform the inherited ways of producing scholarship and constituting our fields. ${ }^{3}$ In the History of Media Studies project, that begins with our Editorial Board, which will be a more participatory body than many such entities, actively shaping the work we do and how we do it. We are very fortunate to have a geographically diverse and remarkably talented board, whose membership will continue to grow. The launch essays they've written here are the most visible signs of their guiding participation in this endeavor, but by no means the only ones. Board members are helping us to imagine and implement a journal guided by the ideals of care, craft, and collegial friendship across borders, directed toward investigating the history of media studies in all its complexities around the world. In that context, the editors of History of Media Studies see our roles as facilitators of a collective process of bringing something new into the world. We are committed to leveraging structural privileges we might have to aid that endeavor and moving forward through dialogical openness to difference and critique.

The Colombian-born anthropologist Arturo Escobar, inspired by the Mexican Zapatistas, has advocated for designing a world for "the pluriverse, a world where many worlds fit." 4 What would histories of media studies written for a pluriverse entail, and how might the
${ }^{3}$ Mohan J. Dutta, "Whiteness, Internationalization, and Erasure: Decolonizing Futures from the Global South," Communication and Critical/Cultural Studies 17 , no. 2 (2020).

\footnotetext{
${ }^{4}$ Arturo Escobar, Designs for the Pluriverse: Radical Interdependence, Autonomy, and the Making of Worlds (Durham, NC: Duke University Press, 2018), xvi.
} 
journal be designed to facilitate them? We don't pretend to know, but we are eager to create spaces for experimentation, and we have a few commitments at this early juncture. One pertains to language, which, as Susana Martínez Guillem writes, is "a fundamental axis of power relations" that should be featured in efforts to re-shape the contemporary field. 5 The marginalization of scholars and scholarship operating in languages outside of English is obvious to anyone outside the English-only center of US-dominated academic fields. As one modest step in a different direction, History of Media Studies will review and publish manuscripts in Spanish as well as English, and we hope to expand beyond those two languages in the future.

A second commitment is to support the writing of histories of media studies from around the world, particularly from the Global South and other regions that have been peripheral, at best, in the English-language historiography to date. This means more than simply generating a fuller record of the history of media studies around the globe, though we believe that's an important goal. It also means supporting historiographical analogues of "theory from the South" that might reorient received ways of writing histories of media studies, or at least help create the sorts of "common spaces with room for differentiation" advocated by proponents of academic cosmopolitanism. ${ }^{6}$ This must be done in ways that don't perpetuate the practice of scholars from the Global North talking about Southern contexts without including voices from the regions. ${ }^{7}$ The commitment also entails "provincializing" the traditionally unmarked particularities that have masqueraded as universals, or at least as the taken-for-granted baseline-histories that, intentionally or not, have presented themselves as histories of the field, when they are really the histories of a handful of successful, institutionally well-placed, and overwhelmingly male scholars who either published in English or were prominent enough to have their work translated.

This in turn opens to a third commitment of the journal: to focus not just on media studies as it has developed within academic institutions, be they core or peripheral, but also on what we call "alter-traditions" of reflective inquiry about media, again broadly conceived. What conceptualizations, educational practices, normative frameworks, and forms of reflective social practice about media have developed outside the academy? Some of these traditions are of course embedded in the commercial sector, and others trace their origins to the work of prominent religious organizations like the Catholic Church. History of Media Studies encourages research that brings these histories into closer conversation with histories of academic media studies; but we particularly encourage work that excavates the alter-traditions of Indigenous and other subaltern groups
${ }^{5}$ Susana Martínez Guillem, "Sacando la Lengua in Rhetorical Theory and Criticism," Rhetoric, Politics \& Culture 1, no. 1 (2021), 45. See also Silvio Waisbord, "Communication Studies without Frontiers? Translation and Cosmopolitanism across Academic Cultures," International Journal of Communication 1o (2016); and Ana Cristina Suzina, "English as Lingua Franca: On the Sterilisation of Scientific Work," Media, Culture \& Society 43, no. 1 (2021).

\footnotetext{
${ }^{6}$ Jean Comaroff and John Comaroff, Theory from the South: Or How EuroAmerica is Evolving toward Africa (New York: Routledge, 2012); and Hanan Badr and Sarah Anne Ganter, "Towards Cosmopolitan Media and Communication Studies: Bringing Diverse Epistemic Perspectives into the Field," Global Media Journal (German Edition) 11, no. 1 (2021).

7 Sarah Anne Ganter and Félix Ortega, "The Invisibility of Latin American Scholarship in European Media and Communication Studies: Challenges and Opportunities of De-Westernization and Academic Cosmopolitanism," International Journal of Communication 13 (2019).
} 
and the reflective cultural practices that represent less-recognized varieties of media study - a body of work that Latin Americans and other scholars from the Global South have been at the forefront of producing, often connected to other kinds of decolonial efforts. ${ }^{8}$

\section{Beyond Open Access}

The journal's mission commitments extend to its mode and manner of publication. History of Media Studies is open access (OA), which means that readers don't pay for articles or subscriptions. In that respect, History of Media Studies resembles many newer journals, even some launched by the big five commercial publishers. The difference, a crucial one for us, is author fees: We don't charge any, on principle. Many open access journals, even those published by scholarly societies, require authors to pay an "article processing charge" (APC) that typically runs $\$ 3,000$ to $\$ 5,000$. Open access for readers, we believe, should not be traded for new barriers to authorship. Instead of author fees, we support our operations through what is commonly called collective funding: direct support from libraries and foundations. 9 What collective funding means is that our submissions are evaluated on their editorial merits, without regard to personal or institutional wealth. Among other things, this fee-free status supports our mission to publish authors and topics from around the world-since most scholars outside a handful of rich North American institutions and wealthy European countries can't afford APCs.

In line with our no-fee policy, we interpret "open access" in a more demanding, value-laden way than the typical scholarly outlet. We believe that ownership and governance matter-that sustainable OA publishing should be nonprofit, community-led, and transparent. Together with our scholar-led publisher, mediastudies.press, we subscribe to Jean-Sebastian Caux's "Genuine Open Access Principles." ${ }^{10}$ We are committed to using open infrastructure wherever possible, which extends to the publishing software itself: PubPub, the MIT-linked open-source platform premised on reclaiming scholarly communication for the academic community. ${ }^{11}$ Our governance and finances are transparent and open for scrutiny, with a special accent on our scholar-led operations. ${ }^{12}$

Our plans to limit the volume of articles we publish-typically no more than ten a year-is a deliberate means to a value-oriented end. As editors, we can afford to take a slow, care-based approach to authors and their submissions. We think of this as a craft ideal, one that consciously resists the harried facelessness that drives most commercial journals. ${ }^{13}$ History of Media Studies substitutes artisanal editing and humane peer review for ScholarOne and the metric tide.
${ }^{8}$ See, for instance, Claudia Magallanes Blanco and José Manuel Ramos Rodríguez, eds., Miradas Propias: Pueblos Indígenas, Comunicación y Medios en la Sociedad Global (Quito: Ediciones CIESPAL, 2016); and Erick R. Torrico Villanueva, Hacia la Comunicación Decolonial (Sucre: Universidad Andina Simón Bolívar, 2016).

\footnotetext{
${ }^{9}$ History of Media Studies is participating in a new approach to bring nonprofit publishers and library funders together on a web-based matching platform. The idea is that librarians and other funders can support publishers on the basis of shared values. The journal is among the participants in the Open Access Community Investment Program (OACIP), organized by the North American library consortium LYRASIS. On the idea of mission-aligned funding exchanges, see Jefferson Pooley, "Collective Funding to Reclaim Scholarly Publishing," The Commonplace, August 16, 2021, https://commonplace. knowledgefutures.org/pub/erpw9udj. ${ }^{10}$ See "Open Access Principles," mediastudies.press, https://www. mediastudies. press/oa-principles; and Jean-Sébastien Caux, "Genuine Open Access Principles," Jean-Sébastien Caux, https://jscaux.org/blog/post/ 2018/05/05/genuine-open-access/.

${ }^{11}$ PubPub is a project of the nonprofit Knowledge Futures Group, which emerged from a partnership between MIT Press and the MIT Media Lab. See “Our Mission," PubPub, https: //www. pubpub.org/about. On the Knowledge Futures Group's vision for scholarly publishing, see Gabriel Stein et al., "Clarivate, ProQuest, and our Resistance to Commercializing Knowledge," The Commonplace,
} 
Our author reports, as one example, don't merely include download and citation counts, but also quoted passages and citation contexts.

The issue of metrics raises what is, for us, an important point. We believe that our care-based ethic is compatible with both editorial quality and best practices in scholarly publishing. Every article receives a Creative Commons license and a DOI, with downloads available in PDF and seven other formats, including machine-readable JATS XML with swift and accurate Google Scholar indexing. ${ }^{14}$ The journal's copy editors are skilled line-editors too, with masthead and article-level credit in recognition of their vital work.

Among our aims is to help broaden what a scholarly article looks like. We chose the PubPub platform, in part, for its extensive support for multimedia formats, on the assumption that historians of media studies might illuminate these fields' pasts in dialogue with new forms of scholarly communication. Consider the typical archivesbased historical paper: We envision publishing archival documents and other supporting media within the articles that cite them. We plan to publish archival collections and half-forgotten public domain works too, anchored by new introductions. We will even re-publish refereed, openly licensed work appearing elsewhere, with linked "Replies" solicited for these "overlay" works as well as for original articles. The journal is open to entire submissions whose arguments are rendered in audio, video, and other non-textual forms.

History of Media Studies' slow-scholarship values also guide our approach to peer review. We are committed to a humane, developmental review process, with the goal to improve manuscripts through collegial exchange. Inspired by the example of Public Philosophy, we see our role as more than reviewer-herders in service of a one-off decision. ${ }^{15}$ We aim to cultivate in reviewers, too, an ethos of ongoing, supportive involvement with an author and her manuscript. History of Media Studies employs double-anonymous review by default, but encourages more open modes at authors' discretion. For example, we support signed review, in which reviewers sign their comments and may continue to consult with authors throughout the revision process. We will also experiment with community review, in which an article draft gets published early in the process, with public, signed comments encouraged - and with iterative revisions supported by PubPub's robust versioning support. ${ }^{16}$

Among our goals is to help foster a far-flung community of scholars working on the history of media studies and its sister fields. We maintain, in cooperation with the journal, a working group on the History of Media Studies. At each monthly session, a scholar presents on a work-in progress in remote sessions attended by academics from around the world. The same welcoming, developmental
May 18, 2021, https://commonplace. knowledgefutures.org/pub/kp8lylos/. ${ }^{12}$ See "Transparency," mediastudies.press, https://www. mediastudies. press/transparency.

${ }^{13}$ For an astute reflection on the interplay between commercial capture and editors' own post-defeat malaise and capitulation, see Mark Gibson, "Editing After Exit-Alienation and CounterAlienation in the Cultures of Cultural Studies Journals," Continuum 35, no. 3 (2021).

${ }^{14}$ Indeed, History of Media Studies, on launch, meets all the compliance criteria for the European funders' "Plan S," including the technical requirements. See cOAlition S, "Plan S Principles," Plan S, https://www. coalition-s. org/plan_s_principles/. The journal's publisher, mediastudies.press, is a member of Crossref, the Open Access Scholarly Publishing Association (OASPA) and the Radical Open Access collective, with vetted affiliations including the Directory of Open Access Books (DOAB), Project MUSE, and OAPEN. History of Media Studies will apply for listing in the Directory of Open Access Journals (DOAJ) and membership in the Committee on Publication Ethics (COPE), when eligible after one year of operation. See "About this Journal," History of Media Studies, 2021, https://hms . mediastudies. press/about.

${ }^{15}$ See "Formative Peer Review (FPR)," Public Philosophy Journal, https://publicphilosophyjournal. org/overview/.

\footnotetext{
${ }^{16}$ See "Peer Review," History of Media Studies, https://hms . mediastudies. press/peer-review.
} 
culture informs the working group, as an extension of the journal's editorial ethos. ${ }^{17}$

\section{A New Journal}

The fifteen short essays in this launch series, authored by Editorial Board members, reflect the values we've outlined here. The journal's commitment to attend to structural inequities and exclusions is reflected across many of the launch essays. Wendy Willems, in her contribution, marks a painful irony in recent attempts to deWesternize and decolonize media studies, which have often silenced the actual histories of the field outside the Global North and longstanding decolonial struggles in the African diaspora. She warns of the dangers of decolonization "becoming an empty metaphor" and challenges historians of the field to move beyond mere inclusion to consider "how the act of including different vantage points challenges, subverts and problematizes" dominant understandings of the field. Armond Towns stakes out complementary ground, reviving a vigorous tradition of Black studies that has been occluded by scholarship that "situated Black life solely in reaction to white racism," and that can be renewed through an "alternative epistemological project that... would require the reorganization of the world as it currently sits." He asks us to read the history of media and communication studies alongside the history of Black studies and see how some currents of the former "developed in fear of Black and decolonial revolution." Decentering the white, Euro-American North from different geo-intellectual ground, Liu Hailong and Qin Yidan ask, "What would have been different if communication study had been born in China?" This opens into their discussion of the particularities of the Chinese field and the possibilities that its recent turn toward media embedded in Chinese experience might signal fresh beginnings.

Other essays in the series take up the geopolitical de-centering of the Global North from different perspectives. Mohammad Ayish's contribution situates the history of media studies in the Arab world's technological, political, and socio-cultural contexts, tracking a shift from a development to an empowerment frame. He draws out transnational and cross-regional entanglements that displace the nation-state as historical locus. In his careful consideration of media studies in Argentina, Mariano Zarowsky reminds us that "to speak of a field of knowledge" such as media studies "implies studying a process of formation rather than starting from pre-existing entities." He brings this process of formation to ground-level, highlighting the importance of "temporal formations and specific biographical contexts," as well as the interaction of regional articulations with
${ }^{17}$ The working group is hosted by the Consortium for History of Science, Technology and Medicine (CHSTM). See "Working Group on the History of Media Studies," History of Media Studies, https://hms.mediastudies. press/ working-group. 
global processes. In his essay, Shiv Ganesh outlines a program for an "area-focused approach" to the history of media studies, with the aim to challenge the twinned ills of "theoretical universalization and methodological parochialism" in these fields. He illustrates the value of the approach with the South Asian case, staking out ground to find alternatives to casting "anything outside Euro-American history being defined largely in terms of its difference." The biography, thought, and rich legacies of Jesús Martín-Barbero are the focus of Raúl Fuentes Navarro's essay. Martín-Barbero's De los Medios a las Mediaciones, Fuentes Navarro argues, would define Latin America "as distinct among Western cultural and linguistic regions." A foundational work in the Ibero-American world that has shaped thinking since its publication in 1987 , the book also provides a map for needed historiography of the field in the region.

Many of the launch essays concern prescriptions and adjustments in historiographical focus or technique. Stefanie Averbeck-Lietz, for instance, probes a project on journalism about the League of Nations to draw out the marginal place of historical methods in German communication and media studies. Along the way, she challenges us to think about the methods by which we write histories of the field and the histories of those methods themselves. Thomas Wiedemann and Michael Meyen, in their essay, reflect on a major German-language project-Biografisches Lexikon der Kommunikationswissenschaft or BLexKom-that they help steward. They trace the historiographical promise and peril that the initiative has exposed, including questions of whose story gets told and by whom. Sarah Cordonnier touches on similar themes in her survey of the historiography of French media research, identifying elisions and "black holes" in the literature. She raises big questions about how to write histories of a field with so many permutations, and whether we can find a way to become " 'contemporaries in discipline' in spite of all the differences." In her contribution, Wendy Leeds-Hurwitz makes the case for "theory groups" as a prism for doing history, one that reveals the social infrastructures that support visibility and influence. She implicitly responds to the question of method that AverbeckLietz raises, making space for using group communication theory to understand the social life of ideas.

Other essays point to productive slippages of the "media studies" label that the journal hopes to amplify. Sue Collins, in her contribution, shows how the study of mediated authority exposes the limits of what "communication" or "film studies" alone could do for us. She advocates that "the history of communication and media studies better integrate film and cultural histories into its corpus." In a similar spirit, Filipa Subtil forcefully demonstrates that the philosophy 
of technology tacitly subtends the history of media studies in ways that should challenge our preconceptions regarding what media are. She urges us to remedy a situation where, with a few exceptions, "historians of media studies have not granted enough attention to the question of technology." Maria Löblich, meanwhile, provocatively blurs the lines between the history of communication studies and the phenomenon of collective identity, allowing cross fertilization of those two scholarly fields. Löblich's project, both analytic and reconstructive, allows us to think about "how communication studies were historically tied to symbolic systems in society and what degree of autonomy they had." Finally, Ira Wagman challenges us to "trouble the history of 'media studies' in as many contexts as possible," drawing out the Miranda Prorsus (the 1957 Papal encyclical on motion pictures, television, and radio) as an illustration of religion as one such context. In so doing, he offers an excellent example of histories that examine the conceptualization and study of media outside academic contexts.

Both individually and as a group, the Editorial Board's launch essays at once exemplify dimensions of the journal's mission and develop it in ways that exceed the imaginations of the editors who formulated it. Plurality has unique potential. Here it is manifest through writing that arises from scholarly lives animated by diverse problematics, thought styles, languages, political cultures, and institutional contexts. We are grateful for their creative responses to our invitation, which we hope you will read and circulate freely, in the spirit of open access.

\section{Bibliography}

"About this Journal." History of Media Studies. https://hms . mediastudies. press/about.

Badr, Hanan, and Sarah Anne Ganter. "Towards Cosmopolitan Media and Communication Studies: Bringing Diverse Epistemic Perspectives into the Field." Global Media Journal (German Edition) 11, no. I (2021): 1-3. https://doi.org/10.22032/dbt. 49164.

Caux, Jean-Sébastien. "Genuine Open Access Principles." JeanSébastien Caux. https://jscaux.org/blog/post/2018/05/05/genuineopen-access.

cOAlition S. "Plan S Principles." Plan S. https ://www. coalition-s. org/plan_s_principles/

Comaroff, Jean, and John Comaroff. Theory from the South: Or How Euro-America is Evolving toward Africa. New York: Routledge, 2012.

Dutta, Mohan J. “Whiteness, Internationalization, and Erasure: 
Decolonizing Futures from the Global South." Communication and Critical/Cultural Studies 17, no. 2 (2020): 228-35. https: //doi.org/10.1080/14791420.2020.1770825.

Escobar, Arturo. Designs for the Pluriverse: Radical Interdependence, Autonomy, and the Making of Worlds. Durham, NC: Duke University Press, 2018.

"Formative Peer Review (FPR)." Public Philosophy Journal. https: //publicphilosophyjournal.org/overview/.

Ganter, Sarah Anne, and Félix Ortega. "The Invisibility of Latin American Scholarship in European Media and Communication Studies: Challenges and Opportunities of De-Westernization and Academic Cosmopolitanism," International Journal of Communication 13 (2019): 68-91. https://ijoc.org/index.php/ijoc/ article/view/8449.

Gibson, Mark. "Editing After Exit-Alienation and Counter-Alienation in the Cultures of Cultural Studies Journals." Continuum 35, no. 3 (2021): 356-68. https://doi.org/10.1080/10304312.2021. 1902159.

Guillory, John. "Enlightening Mediation." In This is Enlightenment, edited by Clifford Siskin and William Warner, 37-66. Chicago: University of Chicago Press, 2010.

Magallanes Blanco, Claudia, and José Manuel Ramos Rodríguez, eds. Miradas Propias: Pueblos Indígenas, Comunicación y Medios en la Sociedad Global. Quito: Ediciones CIESPAL, 2016.

Martínez Guillem, Susana. "Sacando la Lengua in Rhetorical Theory and Criticism." Rhetoric, Politics \& Culture 1, no. 1 (2021): 45-54. https://muse.jhu.edu/article/801950.

"Open Access Principles." mediastudies.press. https://Www. mediastudies. press/oa-principles.

"Our Mission." PubPub. https://www. pubpub.org/about.

"Peer Review." History of Media Studies. https://hms . mediastudies. press/peer - review.

Pooley, Jefferson. "Collective Funding to Reclaim Scholarly Publishing," The Commonplace. August 16, 2021. https://commonplace. knowledgefutures.org/pub/erpw9udj.

Shechtman, Anna. "Command of Media's Metaphors." Critical Inquiry 47, no. 4 (2021): 644-74. https://doi.org/10.1086/714512.

Stein, Gabriel, Travis Rich, Zach Verdin, and Catherine Ahearn. "Clarivate, ProQuest, and our Resistance to Commercializing Knowledge." The Commonplace. May 18, 2021. https:// commonplace. knowledgefutures.org/pub/kp81ylos/.

Suzina, Ana Cristina. "English as Lingua Franca: On the Sterilisation of Scientific Work," Media, Culture \& Society 43, no. I (2021): 17179. https://doi.org/10.1177/0163443720957906. 
Torrico Villanueva, Erick R. Hacia la Comunicación Decolonial. Sucre: Universidad Andina Simón Bolívar, 2016.

"Transparency." mediastudies.press. https://www. mediastudies . press/transparency

Waisbord, Silvio. "Communication Studies without Frontiers? Translation and Cosmopolitanism across Academic Cultures." International Journal of Communication 10 (2016): 868-86. https: //ijoc.org/index.php/ijoc/article/view/3483.

"Working Group on the History of Media Studies." History of Media Studies. https://hms . mediastudies.press/working-group. 